\title{
Concept of the Mechanically Powered Gyrobus
}

\author{
J. Hampl \\ DEKRA Automobil a.s., Passive Safety Laboratory, Kličany 108, CZ 25069 Vodochody, Czech Republic \\ jason.hampl@dekra-automobil.cz
}

DOI: $10.2478 / \mathrm{v} 10158-012-0029-9$

\begin{abstract}
The new gyrodrive concept is an innovation of the mechanical gyrobus transmission by Hampl \& Vítek (2006). The legitimate aim of substituting urban buses with zero emission vehicles is actually very difficult to achieve. First of all, no existing non-rail vehicle for urban mass transport can compete with urban buses in terms of cost. Even trolleybuses on the busiest lines are less economically efficient. In addition, they lack the flexibility of buses. Electrobuses with their heavy and slow to charge accumulators are almost as expensive as fuel-cell buses whose specific problem is refueling with compressed or liquefied hydrogen. A gyrodrive does not face such problems and it is also reasonably safe. But even a modern electric system for power transmission from the flywheel to the driving axle is neither light nor cheap. A mechanical solution with CVT (Continuously Variable Transmission) can be more advantageous. Such a system has been used for the recuperation of braking energy. The mechanical system described in this article uses an IVT system (Infinitely Variable Transmission) for the vehicle drive. If that system is used for flywheel charging at the terminal, it will be connected as a CVT (by using an external three-phase $50 \mathrm{~Hz}$ electromotor). The higher-than-average requirement for transmitted power should be met by the suggested special CVT solution with rigid friction members. Thanks to its planetary configuration it has acceptable dimensions and mass. The slip minimization and the fact that the pressure forces do not load the bearings should ensure good efficiency.
\end{abstract}

KEY WORDS: Gyrobus, mechanical power transmission, CVT, IVT, planetary differential.

\section{INTRODUCTION AND MOTIVATION}

\subsection{History}

The first electrically driven road vehicles independent of a trolley wire were made in Europe and in the USA as early as the late $19^{\text {th }}$ century. These included mainly vehicles with electrochemical current sources. Such sources have prevailed in electrocars and electrobuses up to now. But despite long and concentrated research on electrochemical sources, the relationship between their price and lifetime is still almost unacceptable for use as a vehicle drive. They also have other undesirable attributes: in the case of fuel cells, used now in many experimental vehicles, in particular electrobuses, the main problems concern the distribution and refuelling of expensive hydrogen, whether in compressed or liquefied form (Ingvarsson et al., 2011). Problematic attributes of electrochemical accumulators are as follows: relatively slow charging (particularly towards the end), insufficient reliability, energy capacity reduction during their lifetime, power and exploitable energy capacity linked to temperature and the destructive influence of a deep discharging on the battery lifetime. 
Such disadvantages are not associated with kinetic energy accumulation. However, flywheels have another serious drawback: fast self-discharging, which makes their use in electrocars almost impossible. However, this is not relevant for urban mass transportation vehicles. They have regular and short routes with breaks at terminals where there is enough time for charging the flywheel fully (but not for fully charging any electrochemical accumulator). This is how the idea of gyrobus came about.

The first regular gyrobus transport started in Switzerland in October 1953, on a $4.5 \mathrm{~km}$-route between Yverdon-les-Bains and Grandson. The most extensive use of those gyrobuses was in Leopoldville (today's Kinshasa in the Democratic Republic Congo, Africa) where they operated until 1969.

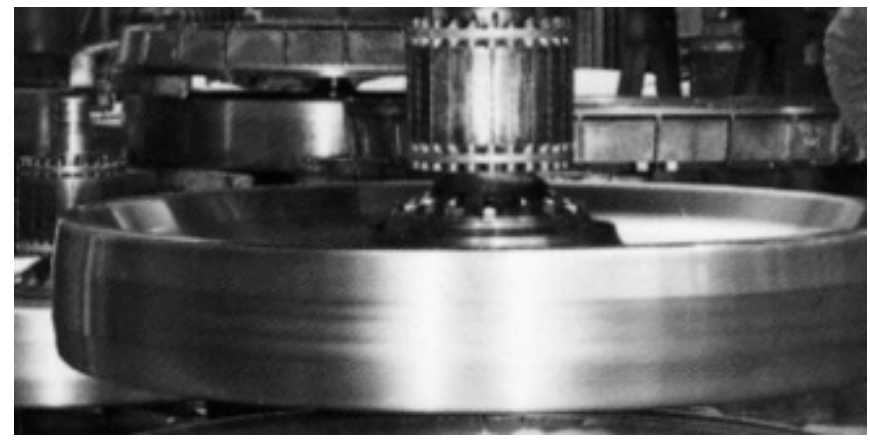

Figure 1: Rotor of the asynchronous motor-generator and steel flywheel of the FMO gyrobus.

Their gyrobus drive was developed by the Swiss company Oerlikon. Its flywheel of compact steel had a vertical rotation axis and an external diameter of $1.6 \mathrm{~m}$. Its mass was $1500 \mathrm{~kg}$. It was coaxially connected to an asynchronous motor-generator. During the "refuelling" (about 4 minutes, $150 \mathrm{~kW}$ ) the motor-generator was powered from the common three-phase $50 \mathrm{~Hz}$ network by using bar collectors on the vehicle roof. The maximum motor speed was $2900 \mathrm{rpm}$ and its minimum operation speed was $2300 \mathrm{rpm}$. Therefore $63 \%$ of the accumulated energy was non-utilizable. When the vehicle was running this asynchronous generator supplied the current to the three-phase asynchronous traction motor. The main control was performed in steps by switching over of the poles.

\subsection{Present Solutions}

Current technology allows a step-less and entirely smooth control of flywheel propulsion over a wide running speed range, and also minimizes the consequences of unlikely material destruction. That is to say that in the area of inertial energy accumulation a lot of theoretical and experimental work has been performed with positive results, particularly in the USA. The new "super-flywheels" make use of light materials such as glass type E, aramid or carbon. In the form of a filament they are extremely strong. A wound flywheel can also accumulate more energy due to the permitted low safety coefficient (a ruptured filament will be disarmed by the flywheel box without endangering passengers or pedestrians).

In order to eliminate ventilation losses such a flywheel runs in a vacuum and it is directly connected to a synchronous motor-generator whose rotor has permanent magnets, e.g. made of Fe-B-Nb alloy (electromagnets would need cooling which is difficult in a vacuum).

One of the first similar solutions was an inertial accumulator developed by NASA for supplying electric energy to satellites when they pass through the Earth's shadow, where the photocells do not work (an electrochemical accumulator would work there for only a few months). Chrysler used 15 of these sources for the powering of an experimental electrocar. 
More significant in this context were additional flywheel units for urban buses or trolleybuses used together with main energy sources to cover the peaks in consumption and for regenerative braking (possibly also for a short independent drive). Such units were installed by the Magnet Motor GmbH in two urban buses in Munich in 1988, and in twelve trolleybuses in Basle in 1992. Their carbon filament flywheels had a maximum speed of 12,000 rpm. Their relatively high extra mass was also unfavorable for use in road vehicles.

The Kinetic Energy Recovery Systems (KERS), with a mechanical transmission of power using CVT, are lighter. For example, the company Hybrid Automotive Limited has developed the Flywheel Hybrid System for Premium Vehicles (FHSPV for Jaguar XF prototype). Another of their sets designed to meet the FIA regulations for Formula One is shown in Fig. 2. Its accumulated energy is $400 \mathrm{~kJ}(60,000 \mathrm{rpm})$, its additional power $60 \mathrm{~kW}$ (limited by its toroidal CVT). Its total weight is $25 \mathrm{~kg}$ and volume 13 litres.

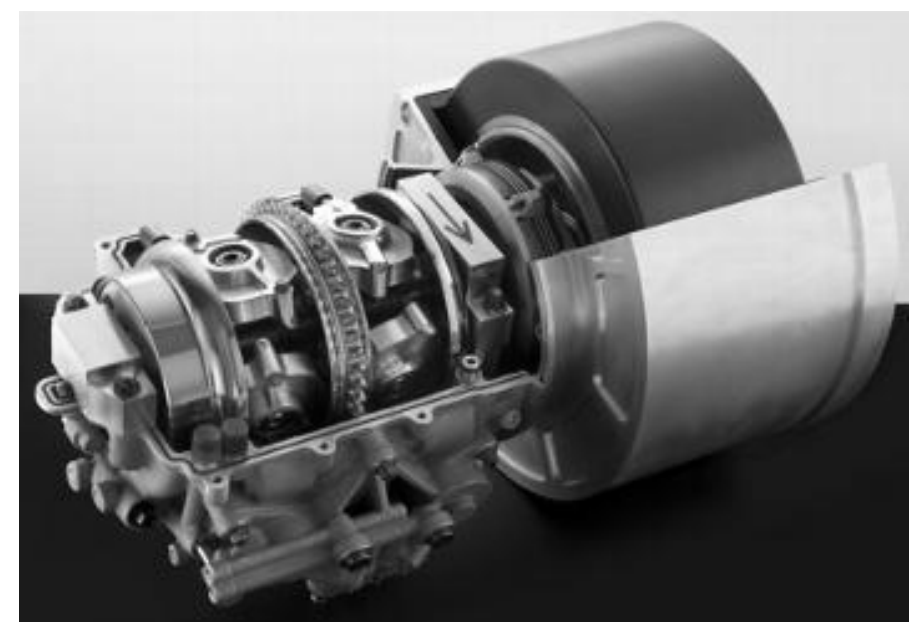

Figure 2: Flywheel unit combined with the TOROTRAK CVT as auxiliary drive for F1 racers.

Concerning rail vehicles, the increased price due to the installed flywheel unit is not dramatic and the mass increase is hardly relevant. Therefore, an auxiliary flywheel unit made by the rosseta Technik GmbH was installed into the LIREX articulated train produced by Alsthom LHB. Its carbon fibre flywheel had a net mass of $160 \mathrm{~kg}$, a maximum speed of 25,000 rpm, a maximum accumulated energy of $6 \mathrm{kWh}$ and a maximum output of $350 \mathrm{~kW}$. Its specific energy of $135 \mathrm{~kJ} / \mathrm{kg}$ was comparable to that of CD-Ni accumulators. (The new lithium batteries, e.g. $\mathrm{LiFePO}_{4}$, have a higher specific energy but such a flywheel can outperform them in terms of power. Its lifetime, measured in cycles, is more than 1,000 times longer.)

The flywheel together with the rotor of the motor-generator runs in its box on ball-bearings lightened by permanent magnets. The bearing losses do not exceed $200 \mathrm{~W}$ but the losses in the motor-generator during its idle run were $3.5 \mathrm{~kW}$ (causing fast self-discharging). Therefore, the producer recommended its use only for applications where charging or discharging lasts only about ten minutes. Our intention is to significantly extend that time by a radical restriction of selfdischarging so that the flywheel could be used as the only energy source for the gyrobus drive. Furthermore, we want to increase the total efficiency (Dede et al., 2012) and reduce the mass of the entire gyrobus propulsion unit to the level of a standard bus engine-gearbox assembly. We also aspire to cut the price of the unit.

\section{PRINCIPLE OF THE NEW GYROBUS DRIVE}

We expect to use a nearly identical design for the composite flywheel as noted above but we will replace the electric power transmission from the flywheel to driving wheels 
with a fully mechanical one. An Infinitely Variable Transmission (IVT) will be used for this purpose. This should result in a substantially decreased self-discharging, increased total efficiency and a smaller mass. The price is also expected to decrease.

A disadvantage of the mechanical transmission is the leeway loss due the dislocation of drive components in the vehicle. Concerning the placement of the flywheel, a parallel orientation of its rotation axis to the vehicle's transverse axis would be favorable because if the flywheel rotation is reverse to the vehicle wheels rotation the gyroscopic moment counteracts the tilting torque of the centrifugal force during vehicle turning (Shaobo \& Shuyun, 2012). The rpm has a linear influence on the gyroscopic moment but a quadratic influence on the accumulated energy. So, if a high speed flywheel and a low speed one have the same accumulated energy, the high speed flywheel will have a lower gyroscopic moment. Therefore, its axis orientation is not very important (for example, in the case of our gyrobus the maximal lateral force on the axles generated by both flywheels during very rapid turning of the vehicle can reach approx. $1 \mathrm{kN}$ ).

Due to the low-floor concept the drafted gyrobus has an individual drive for each rear wheel. Therefore, two flywheels are used. They are placed tplajerogether with the IVT systems under fours of passenger seats $(2+2$, dos à dos on the elevated floor). Similarly, under the next four seats the driving wheels are situated, see figure 3:

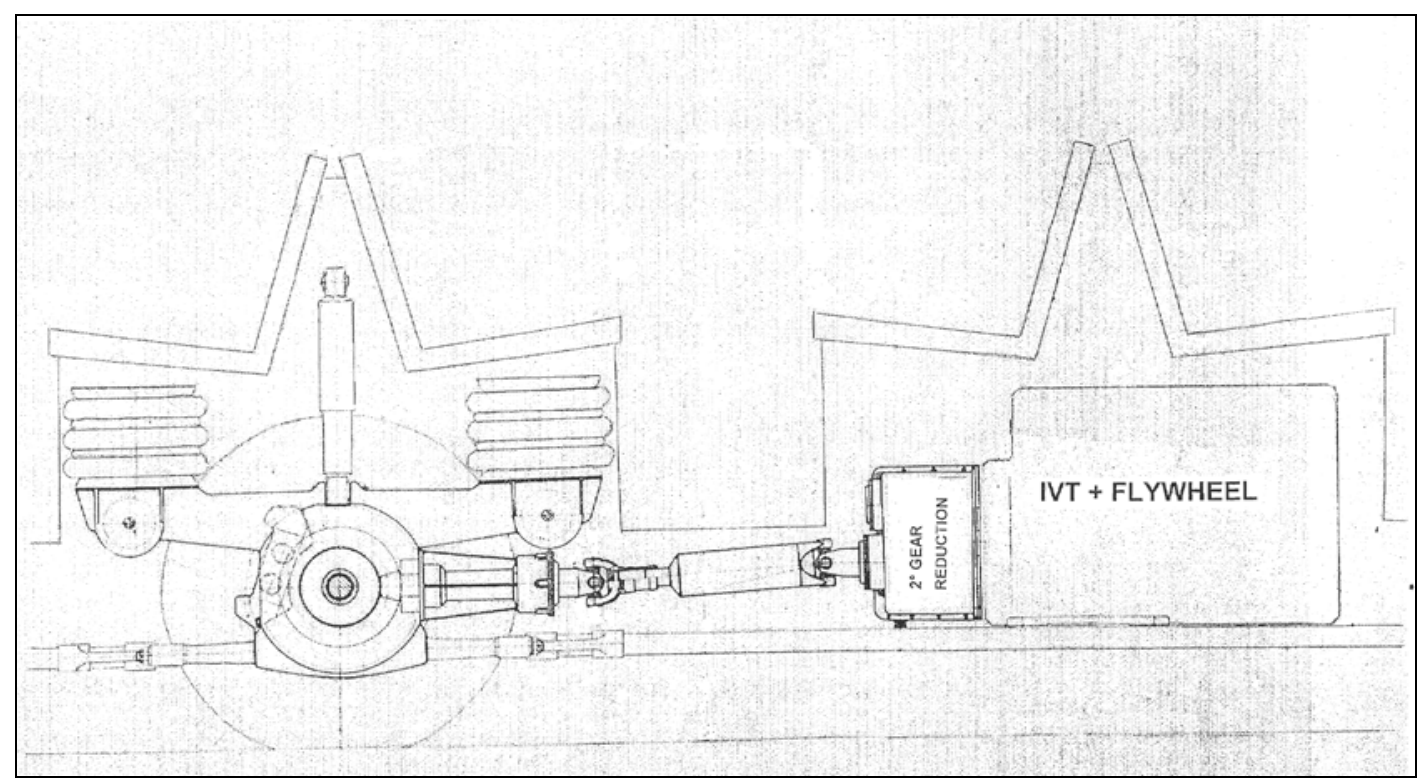

Figure 3: Scheme of individual drive for each of both rear wheels of the low floor gyrobus.

The flywheel rotational axes are parallel with the longitudinal axis of the vehicle. The special drive of the rear wheel is illustrated in figure 4.

In order to minimize ventilation losses there will be a vacuum in the flywheel box and rarefied hydrogen in the IVT box. Compared to air, hydrogen has half the kinematic viscosity, 14 times lower specific mass and better conducts away the heat produced. The vacuum in the flywheel box must be renewed by an on-board exhauster (at terminals only). The hydrogen infiltrates into the flywheel box from the IVT box along the shaft sealing, and into the IVT box from the bearing inter-space where it is replenished from a small container. The filling pressure must be slightly higher than the atmospheric one so that no explosive mixture can result due to air penetrating from the outside. 


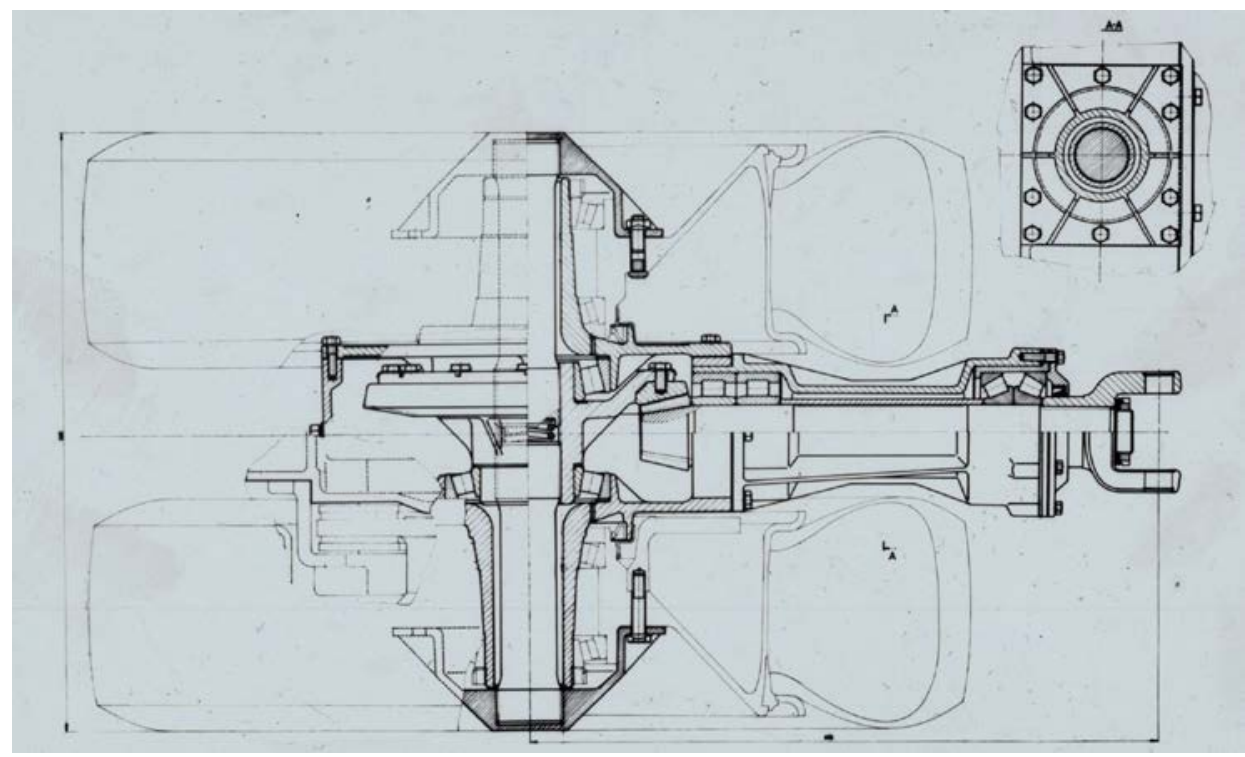

Figure 4: Special drive of the rear wheel (inner tyres are mountable from the vehicle interior).

\section{THE NEW CVT AND ITS OPERATION AS IVT}

Currently produced CVTs are installed into cars with a considerable output surplus available so that the CVTs mostly transmit only a small part of the presented maximum torque. Also, the number of service hours is far lower for cars than for urban buses. Therefore, such CVTs would not work well for a gyrobus. However, this is not the only reason - they are not high-speed enough either.

Therefore, our draft considers an IVT that is based on the planetary CVT presented in figure 5 (next page). This planetary CVT outdoes existing CVTs with rigid friction members by:

- small dimensions, mass and moment of inertia in relation to the transmitted torque;

- allowing transmission of big tangential forces due to a high number of contact facets between the friction elements (48 co-operating facets between disks and doublecones);

- a total absence of the "spin" slip type;

- using the mechanical transmission ratio control (energy savings due to the absence of a hydraulic pump);

- a small slip forced by geometry ("creep" type) due to the differential linkage of the parallel friction elements as are illustrated in figure 6;

- axial pressure forces (figure 7) avoiding the bearings; it ensures, together with the small slip, good efficiency;

- a low value of Hertzian pressure between (see figure 8); the maximum Hertzian pressure (1.35 GPa - TOROTRAK admits $4 \mathrm{GPa}$ ) is achieved in sporadic cases only: when a big output at the minimum operating r.p.m. is required during the maximum or minimum transmission ratio; this ensures the long life of friction elements without requiring any extremely high quality material for them. 


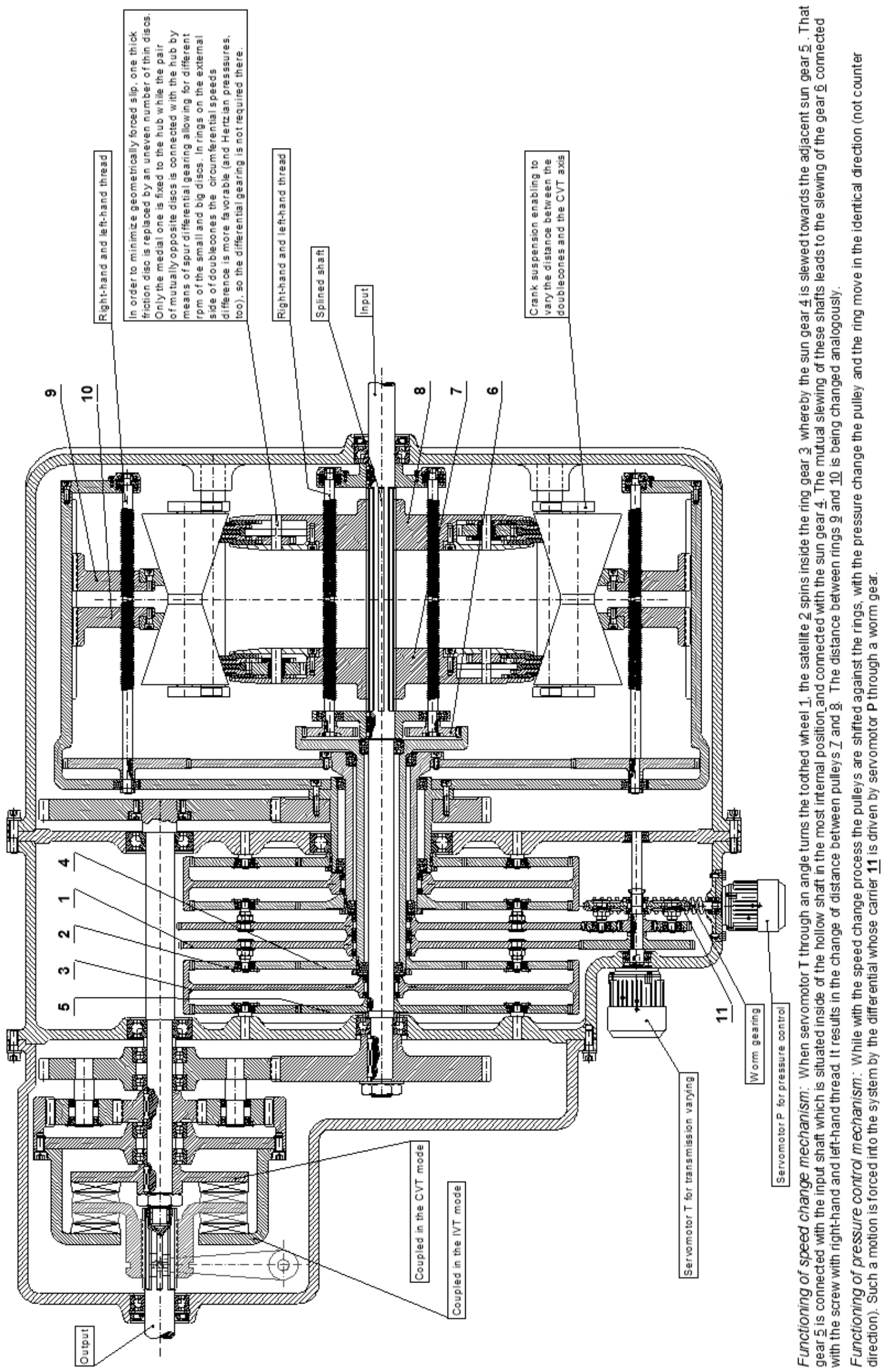

Figure 5: Hypothetic scheme of mechanically controlled IVT (both pressure and gear ratio are actuated). 


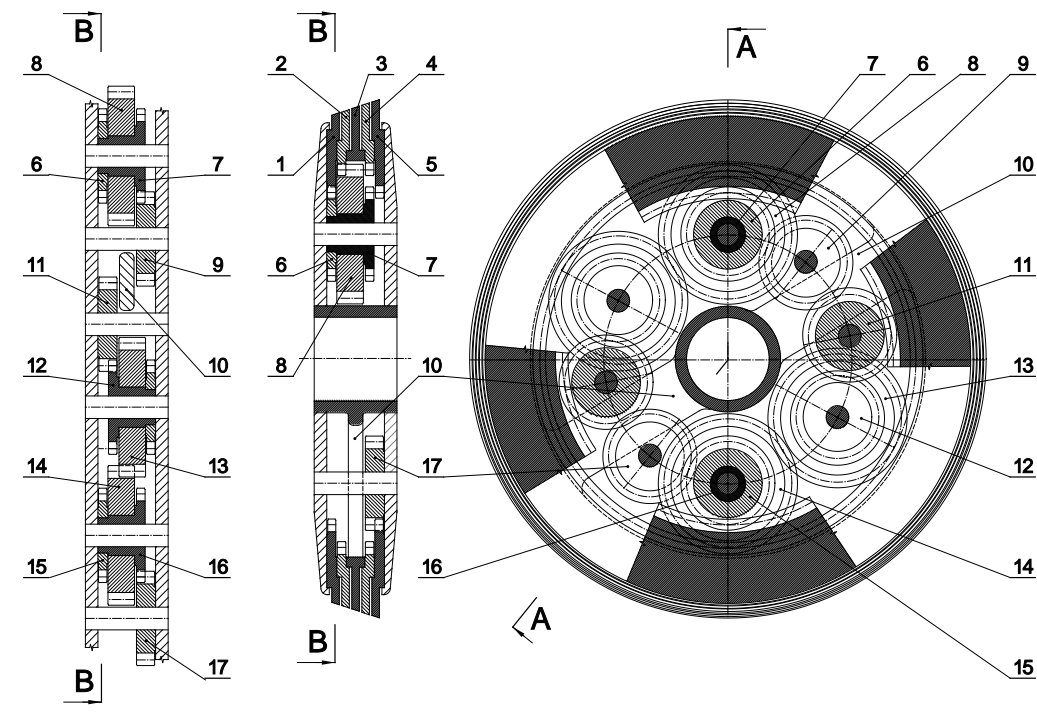

Figure 6: The conic pulley composed of discs forced to rotate with uneven rpm when rolling.

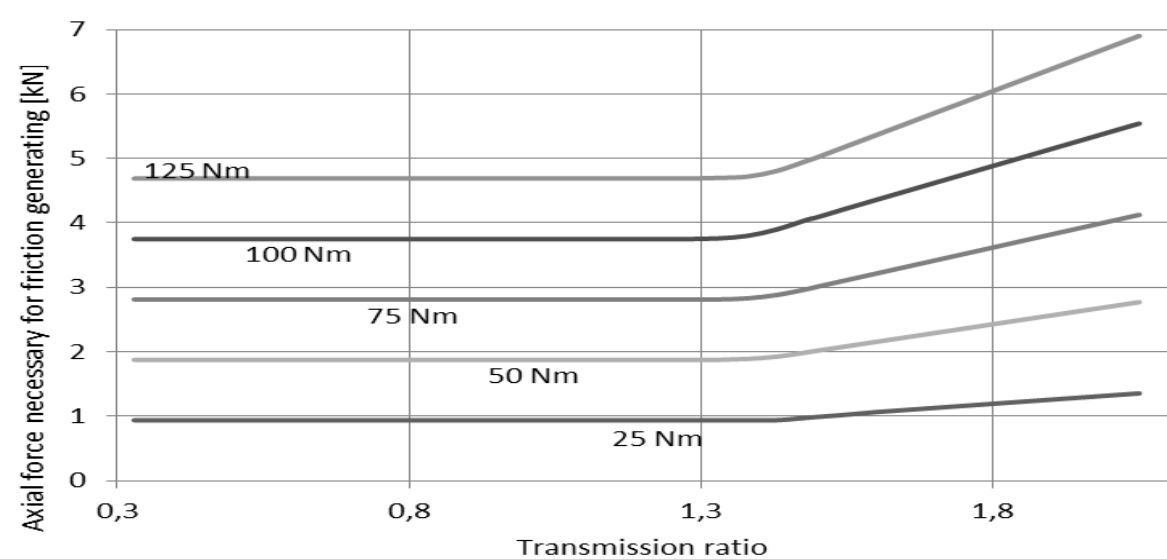

During the rotation and at a steady transmission ratio the axial forces between rings and double-cones are equal as between pulleys and double-cones (the rotation "nullifies" the friction in direction of the cone surface straight line). In the horizontal parts of curves the input torque requires bigger axial force than the output torque and vice versa in the inclined parts.

Figure 7: Axial forces between friction members depending on torque and transmission ratio.

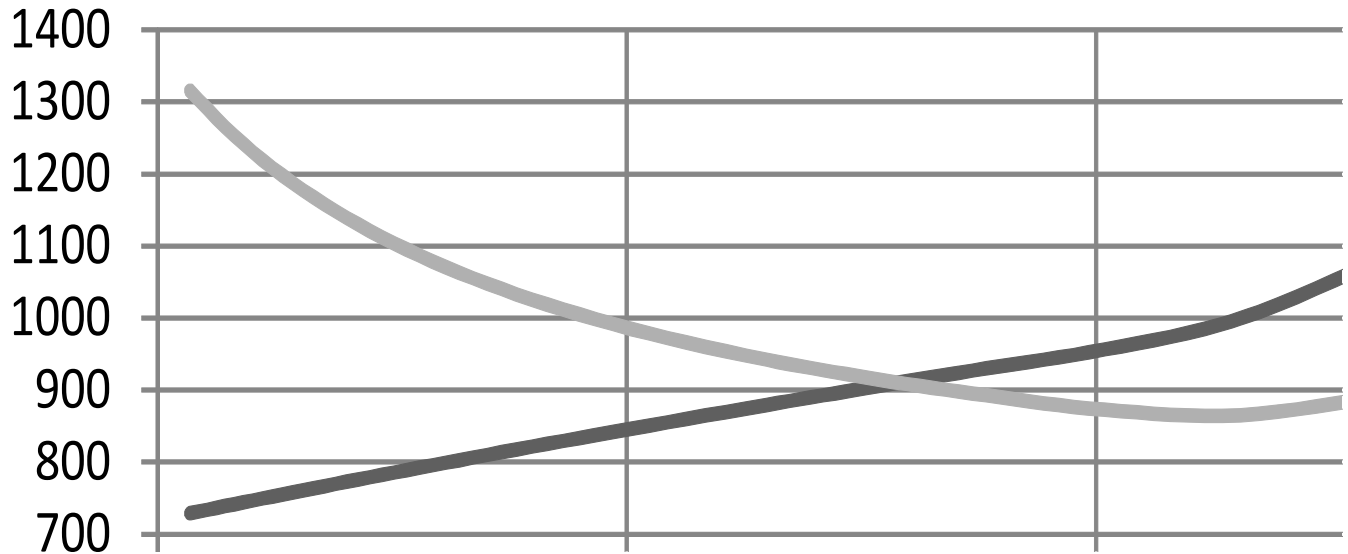

Figure 8: Hertzian pressures [MPa] at maximum input torque (125 Nm). 
The mechanical control of the transmission ratio change is implemented by a mutually opposite shift of friction disks (and rings) by means of screws with right-hand and left-hand threads (Fig. 5). This ensures a permanent perpendicularity of pulleys and rings to the rotational axis during their shift. The mechanism concerned is driven by an energy saving electric servomotor. Mechanical actuation is also used for the mutual thrust of friction members by using a worm gearing for the second servomotor. This type of self-locking gear makes it possible to nullify its incoming power when the thrust maintains a steady value.

\subsection{Modes of Transmission System}

It is not possible to control the speed of a gyrobus (unlike bus and trolleybus) by varying the power source rpm. There is only one method for doing this: continuous varying of the transmission ratio. The variability range must be considerable, also owing to counteractive changes (when the vehicle speed increases the flywheel rpm goes down and vice versa).

For our purposes current mechanical CVTs have insufficient transmission ratio. We can extend the ratio if the CVT collaborates with a differential, changing the transmission into an IVT (Infinitely Variable Transmission). Then the vehicle can move without using a clutch and it will be possible to decelerate and stop without using friction brakes. In the IVT mode the flywheel will be connected to the differential in two ways: both directly (e.g. with the planet carrier) and by means of CVT (e.g. with the sun wheel). Then three different modes can be identified at the output (ring gear):

- Pseudo-locking mode. Although the connection of the flywheel with the vehicle driving wheels is not interrupted the vehicle is stopped as if the parking brake had been used. In this mode the sun wheel (driven by the CVT) turns round faster than the planet carrier in order for satellites to roll in the stopped ring gear. Such a situation occurs when the CVT transmission ratio is nearly the quickest one.

- Reverse. The absolutely quickest CVT transmission ratio is used (the return motion does not require any gear shifting).

- Driving forwards. When the CVT transmission ratio starts getting slower (from the pseudo-locking mode) the sun wheel rpm decreases; however, without any rpm change of the planet carrier connected to the flywheel. Therefore, the ring gear starts rotating in the same direction as the planet carrier and the sun wheel. The vehicle starts moving forwards.

During the pseudo-locking mode the output taken from the flywheel circulates inside the IVT and the energy is being dissipated by its internal resistances. Nevertheless, the IVT output torque $M_{\text {out IVT }}$ is several times bigger than the CVT output torque $M_{\text {out } C V T}$ (in a situation where the differential operation is disconnected and when only the CVT is working). The corresponding multiplication factor depends on the efficiency $\eta$ of the circuit in which the energy circulates.

$$
\mathrm{M}_{\text {out IVT }}=\mathrm{M}_{\text {out CVT }} * \eta /(1-\eta)
$$

The multiplication factor of the torque decreases by moving away from the zero transmission ratio, and the energetic efficiency increases. However, it remains significantly worse than without differential linkage.

Therefore, we disconnect the differential linkage after the transmission range depletion towards the slow output rpm. The IVT will, therefore, change into the CVT, which has better efficiency. Before disconnection the ring gear rpm increase to the level of the planet carrier rpm due to the deceleration of the sun wheel rotation (the rpm of the sun wheel and ring 
wheel equalize) and so the planetary gear set start to revolve as a whole. Consequently, the changeover of the output withdrawal from the sun wheel to the ring wheel runs totally without shock. After the shifting, the CVT transmission ratio starts to return from the slowest value to quicker values causing the vehicle to accelerate.

Automatic stepped gearboxes present the problem of undesirable alternating upand downshift at the boundary between adjacent speed gears. Vehicles with combustion engines have solved the problem by shifting up at a higher vehicle speed than for downshift. This is not possible for a gyrobus with mechanical transmission because a shock-free shifting between IVT and CVT is possible only during the slowest CVT transmission ratio. The alternating gearshift mode cannot be totally excluded but the probability of its occurrence is very low. It can only arise when the change of flywheel rpm is exactly identical to the change of the vehicle speed during the slowest CVT transmission ratio. Furthermore, such an alternating gearshift represents no danger for the driving system. Only the driver would notice it and he can easily stop it (a tiny change of power would be enough).

The driver sets the required value of the output torque using the accelerator. The difference between the required and the actual value determines the velocity of the transmission ratio change and, consequently, the flywheel deceleration. The same applies to the brake pedal in the recuperative braking mode when the flywheel accelerates.

Both the driving force and recuperative braking force will be limited by the control system:

- if the maximum value of the CVT torque is achieved,

- if the maximum vehicle speed is achieved,

- if the set maximum output is achieved (so that the vehicle dynamics are not influenced by the level of the flywheel charge).

\subsection{Energy Recharging}

The most important part of the charging station at the terminal are two common three-phase two-poles electromotors with a short-circuit armature, 50/60 Hz, $6 \mathrm{kV}$, approx. $150 \mathrm{~kW}$, connected to the gyrobus by sheathed articulated shafts. During charging their non-variable rpm are changed into ascending rpm of the flywheel by the same CVTs used to drive the vehicle after moving off (during charging the differential linkage changing CVT into IVT will not be used). Unlike an electrochemical accumulator, the charging accelerates with the increased accumulated energy. Full charging takes 4-5 minutes.

If, exceptionally, it is necessary to start running the flywheel from a total standstill, the external electromotor will also start running from standstill (with Y-connection).

At the terminals, the on-board $24 \mathrm{~V}$ (or $42 \mathrm{~V}$ ) $\mathrm{LiFePO}_{4}$ battery will be charged from an onboard quick-charger connected to the external 220/380 V network together with a quick-charging heat reservoir (approx. $75 \mathrm{~kW}, 5 \mathrm{kWh}$ ) and with the exhauster and air-compressor electromotor.

\section{SAFETY OF GYRODRIVE}

\subsection{Reduction of Damage Caused by Flywheel Collapse}

With regard to the high circumferential speed of the flywheel (up to $2800 \mathrm{~km} / \mathrm{h}$ ) it is necessary to protect the flywheel box from ruptured fibres (Wisnom et al., 2010). The moment of friction could even release the flywheel box from its attachment. In order to protect the box we use a thin ring of carbon laminate which has a little smaller diameter then the flywheel box inside. The pressure of the ruptured fibres extends the ring diameter, 
so the ring presses on the box and the flywheel decelerates intensively. Graphite coating on the outer surface of the ring reduces the friction coefficient and improves the heat removal. The kinetic energy of $39 \mathrm{MJ}$ of the fully charged flywheel would change 15 liters of $20{ }^{\circ} \mathrm{C}$ water into $100{ }^{\circ} \mathrm{C}$ steam. Therefore the flywheel box will be surrounded by a housing and through the so-created interlayer a coolant will flow. Definitely, the emergency flywheel deceleration will be more intensive if air is let in Ribeiro et al. (2012).

\subsection{Flywheel Safety in Case of a Vehicle Accident}

The obligatory most severe destructive test of a bus (which applies to a gyrobus) is the overturning test according to Regulation No. 36 ECE. Such an accident represents no danger for the flywheel if situated outside the deformation zone. This Regulation does not require barrier crash tests. With respect to a bus impact into a non-deformable barrier $(50 \mathrm{~km} / \mathrm{h})$, the specialists' opinion is that the deceleration of the vehicle frame should not exceed $400 \mathrm{~m} \cdot \mathrm{s}^{-2}$ during approx. $50 \mathrm{~ms}$ (stopping distance approx. $1 / 2 \mathrm{~m}$ ).

Such a deceleration represents no problem with respect to the flywheel, its box and the attachment to the vehicle frame, but the choice of bearings is not straightforward. The energy losses of robust bearings are definitely not negligible. Therefore, relatively small ball-bearings are used, supported by permanent magnets. When a vehicle impact occurs, the floppy part of the flywheel box which houses the outer bearing rings will experience an elastic deformation. Thus, the rotating shaft bears on a robust friction bearing which had not operated before due to large clearance. The calculated shock force of $0.2 \mathrm{MN}$ will require about $150 \mathrm{~cm}^{2}$ of sliding surface.

\section{ASSUMED MAIN PARAMETERS OF THE GYROBUS DRIVE}

The preliminary calculations considered a haul length of $12 \mathrm{~km}$ (Mazloumi et al., 2012) and the energy taken away from two flywheels of a two-axled gyrobus of $78 \mathrm{MJ}$. At present, composite flywheels achieve a specific energy of $150 \mathrm{~kJ} / \mathrm{kg}$ (theoretically $673 \mathrm{~kJ} / \mathrm{kg}$ ). So the net mass of two flywheels will be $520 \mathrm{~kg}$ (estimated mass of the whole driving system will be about $1200 \mathrm{~kg}$ ). The power losses of freely rotating flywheels will probably not exceed $0.5 \mathrm{~kW}$ and so self-discharging would only present a problem if the drive interruption lasts more than one or two hours. The friction coefficient between the friction members lubricated by a special oil was estimated to be $f=0.05$ (following the experience of the TOROTRAK company). That reduces the friction losses under the theoretical values shown in figure 9:

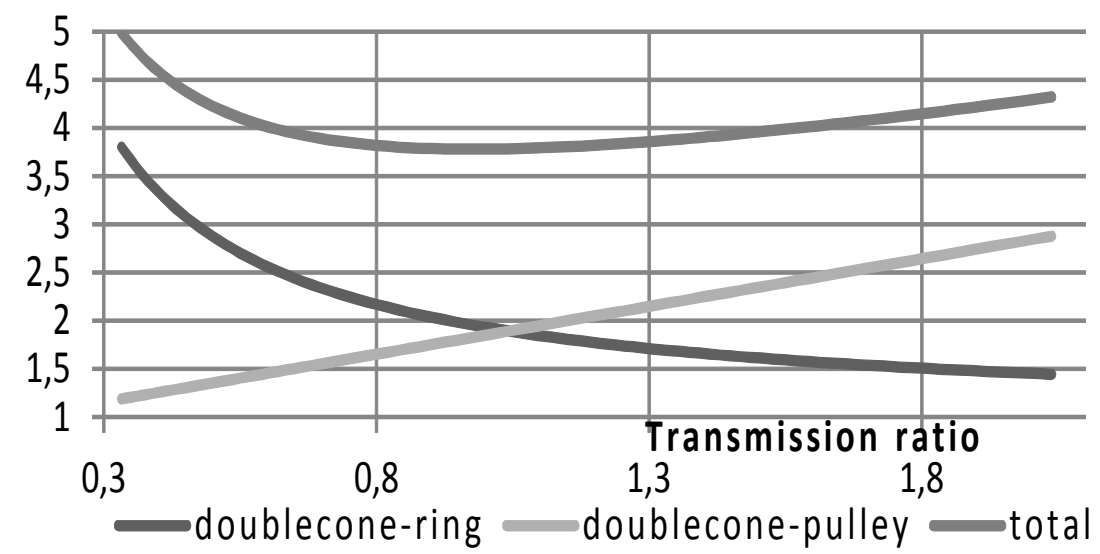

Figure 9: Slip [\% ] caused by the geometry of friction members rolling. 
The selected value of the maximum output from the shaft of each flywheel is $110 \mathrm{~kW}$. If it is supposed to be available also at a minimum operating speed of $8400 / \mathrm{min}$ (maximum 25000/min) then the input torque of the CVT will be 125 N.m (in all other modes it will be lower). With the rpm decreasing to $8400 / \mathrm{min}$ each flywheel still holds $4.4 \mathrm{MJ}$ of energy (11.3 $\%$ ), which may be used for a short emergency. Taking the torque 125 N.m into account, the diameter of the IVT box will be about $300 \mathrm{~mm}$.

Even at minimum operating rpm the required maximum vehicle speed is $70 \mathrm{~km} / \mathrm{h}$. The corresponding minimum vehicle speed in the CVT mode will be $12.9 \mathrm{~km} / \mathrm{h}$ (the transmission ratio range according to the drawing is 5.43). With fully charged flywheels it will be $38.4 \mathrm{~km} / \mathrm{h}$. In that case, or if only a little energy is depleted, a slower drive will have to use the IVT mode, consequently with a lower efficiency (Meulen, 2012).

That is why the drive of each rear wheel is equipped with an additional two-speed gearbox. If its low gear $(\mathrm{i} \approx 5.5)$ is used and the flywheel energy is maximal, already at approx. $7 \mathrm{~km} / \mathrm{h}$ the less economical mode IVT will be changed to the more economical mode CVT. When the speed exceeds $39 \mathrm{~km} / \mathrm{h}$, the high gear $(i=1)$ will be used.

Gear shifting is not simultaneous for both drives of rear wheels. The transmission ratio of one drive is changed at a lower speed than for the other. If shifted, the driving force is interrupted and therefore the torque for the driven other wheel is boosted (controlled by ASR).

The planetary gear set turning a CVT into an IVT (in the differential mode) has wheels with a number of teeth in the ratio of $t_{\text {sun gear }}: t_{\text {carrier }}: t_{\text {ring gear }}=14: 24: 62$.

Our draft has used rough calculations only. The following problems have not been solved at all:

- Providing for a pressure balance of parallel disks on the double-cones;

- A concept of a comprehensive control system, including a sensor for load torque;

- Transmission scheme for charging;

- Heat removal.

\section{EXPECTED ADVANTAGES}

- A cost-saving when substituting city buses with equally flexible zero emission vehicles;

- Reduced operating costs for routes where the substitution has been implemented;

- A more economical use of non-renewable sources (Shepherd, 2008); for example, in the Czech Republic almost 30,000 tonnes of diesel fuel could be saved annually;

- Reduced GHG emissions (Andress et al., 2011) - yearly about 60,000 tons of $\mathrm{CO}_{2}$, 2,000 tons of $\mathrm{NO}_{\mathrm{x}}$;

- The possibility of utilizing the developed IVT also in other areas (e.g. ground machines, military vehicles, trucks etc.

\section{REFERENCES}

Andress, D. et al., 2011. Reducing GHG emissions in the United States' transportation sector. Energy for Sustainable Development, 15 (2), pp. 117-136. ISSN 0973-0826.

Berkel, K., 2012. Optimal Control of a Mechanical Hybrid Powertrain. IEEE Transactions on Vehicular Technology, 61 (2), pp. 485-497. ISSN 0018-9545. 
Boschmann, E., E., Kwan, M.-P., 2008. Toward Socially Sustainable Urban Transportation: Progress and Potentials. International Journal of Sustainable Transportation, 2 (3), pp. 138-157. ISSN 1556-8318.

Dede, E. M. et al., 2012. Computational methods for the optimisation and design of electromechanical vehicle systems. International Journal of Vehicle Design, 58 (2-4), pp. 159 -180. ISSN 0143-3369.

Hampl, J., Vítek, 2006. A New Concept of Infinitely Variable Transmission for Mechanically Powered Gyrobuses. Mecca, 4 (1+2), pp.18-27.

Ingvarsson, A. et al., 2011. A Global Assessment of Hydrogen for Future Automotive Transportation: Projected Energy Requirements and $\mathrm{CO}_{2}$ Emissions. International Journal of Sustainable Transportation, 5 (2), pp. 71-90. ISSN 1556-8318.

Mazloumi, E. et al., 2012. Exploring the Value of Traffic Flow Data in Bus Travel Time Prediction. Journal of Transportation Engineering, 138 (4), pp. 436-446. ISSN 0733947X.

Meulen, S., 2012. Improving Continuously Variable Transmission Efficiency with Extreme Seeking Control. IEEE Transactions on Control Systems Technology, 20 (5), pp. 13761383. ISSN 1063-6536.

Potter, S., 2007. Exploring Approaches Towards a Sustainable Transport System. International Journal of Sustainable Transportation, 1 (2), pp. 115-131. ISSN 1556-8318.

Ribeiro, M. L. et al., 2012. A new damage model for composite laminates. Composite Structures, 94 (2), pp. 635-642. ISSN 0263-8223.

Rosseta Technik Gmbh, 2013 [online]. (C) Frank Täubner [cited 2013-02-12]. Retrieved from: http://www.rosseta.de/

Shaobo, W., Shuyun, J., 2012. Optimum design of hybrid composite multi-ring flywheel rotor based on displacement method. Composites Science and Technology, 72 (9), pp. 982-988. ISSN 0266-3538.

Shepherd, S. et al., 2008. The Effect of Oil Prices on Transport Policies for Europe. International Journal of Sustainable Transportation, 2 (1), pp.19-40. ISSN 1556-8318.

Su, J., Rogers, M., 2012. The Role of Economic Variables and $\mathrm{CO}_{2}$ Emissions in Examining the Efficiency of National Transportation Systems. International Journal of Sustainable Transportation, 6 (1), pp. 48-66. ISSN 1556-8318.

Torotrak, 2013 [online]. (C) 2013 Torotrak plc. [cited 2013-02-12]. Retrieved from: www.torotrak.com

Wisnom, M. R. et al., 2010. Scaling Effects in Notched Composites. Journal of Composite Materials, 44 (1), pp. 195-210. 